The Spectrum of

\title{
NREL's System Advisor Model Simplifies Complex Energy Analysis
}

The energy market is diversifying. In addition to traditional power sources, decision makers can choose among solar, wind, and geothermal technologies as well. Each of these technologies has complex performance characteristics and economics that vary with location and other project specifics, making it difficult to analyze the viability of such projects. But that analysis is easier now, thanks to the National Renewable Energy Laboratory (NREL).

NREL has developed a tool — the System Advisor Model (SAM) — that can help decision makers analyze cost, performance, and financing of any size grid-connected solar, wind, or geothermal power project. Manufacturers, engineering and consulting firms, research and development firms, utilities, developers, venture capital firms, and international organizations use SAM for end-to-end analysis that helps determine whether and how to make investments in renewable energy projects. Initially launched as the Solar Advisor Model, the unbiased analysis provided by SAM proved so popular that the tool was expanded to address additional renewable energy technologies.

SAM grew from a collaborative, five-year effort led by NREL in partnership with the U.S. Department of Energy; Sandia National Laboratories; the University of Wisconsin, Madison; and others. Over tens of thousands of hours, the SAM team refined existing performance and financial models and combined them with new ones to create the powerful yet user-friendly modeling platform. Several key capabilities in SAM had not been available before. Due to these extensive capabilities, SAM has been downloaded more than 25,000 times worldwide since its debut in 2005.

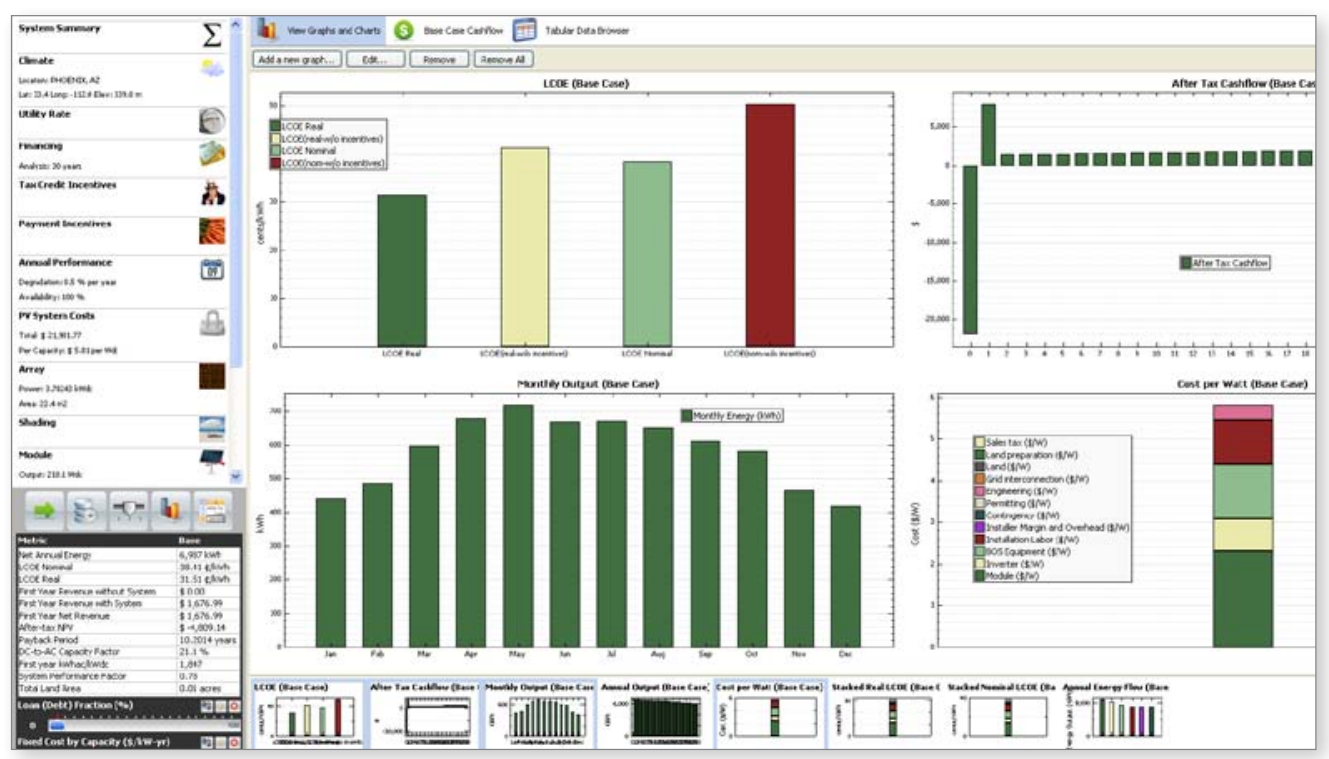

SAM's user-friendly interface is designed to help guide decision makers through the steps of analyzing the energy outputs and economics of a solar, wind, or geothermal project.

Clean Energy Innovation

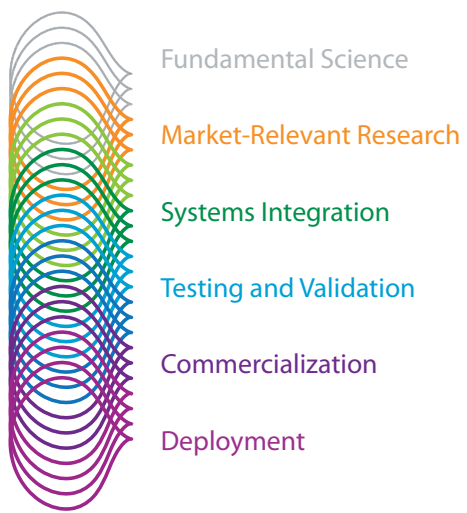

Through deep technical expertise and an unmatched breadth of capabilities, NREL leads an integrated approach across the spectrum of renewable energy innovation. From scientific discovery to accelerating market deployment, NREL works in partnership with private industry to drive the transformation of our nation's energy systems.

This case study illustrates NREL's innovations and contributions in Market-Relevant Research through Deployment



NREL is a national laboratory of the U.S. Department of Energy, Office of Energy Efficiency and Renewable Energy, operated by the Alliance for Sustainable Energy, LLC. 
SAM can now model the gamut of solar electric technologies, including both photovoltaic solar modules and concentrating solar power (CSP) technologies, which include parabolic troughs, dish/Stirling systems, and solar power towers. SAM even calculates the value of saved energy from a domestic solar water heating system. In addition, SAM can model grid-connected small wind and geothermal projects. Plus, the tool includes a simple fossil-fueled power plant model to use in studies comparing renewable technologies to fossil fuels.

\section{How it Works}

SAM is a free, user-friendly, thorough, and extremely fast software tool that allows decisions about renewable energy projects to be made more quickly and more soundly. It starts with information about weather at the project site and calculates the hourly, monthly, and annual electrical output of a proposed energy system. Builtin financial models then calculate a project's cash flow over a multi-year analysis period. SAM even incorporates the effects of state and federal incentives-one of the only energy modeling tools to do so.

With SAM's highly intuitive interface, users can explore in real time how variations in technology parameters, finance options, and performance affect project outcomes across residential, building, and utility-scale markets. SAM's individual models for photovoltaic modules and inverters, CSP solar fields and thermal storage, etc., were validated against measured data, and the overall model was validated against actual system performance data.

\section{A Powerful Tool for All Types of Users}

For people new to renewable energy technologies or to computer modeling, SAM offers technology- and market-appropriate default values for every entry box, which makes it easier to get started using the software. For more experienced modelers, SAM allows detailed inputs and advanced capabilities to explore the intricacies of system design or project financing.

Running SAM generates standard or user-customized summary graphs that can demonstrate the economics of the project. A slider bar feature lets users slowly increase or decrease a variable and watch real-time changes in the graphed results. This ability to do "what if" simulations makes SAM an extremely valuable interactive tool for everyone in the renewable energy marketplace.

By combining renewable energy technology parameters with financial analyses, SAM helps installers, financiers, and developers predict the economic feasibility of proposed projects. More importantly, SAM makes it possible for these groups to work with the same data.

\section{Looking Ahead}

The potential for renewable energy development has never been greater. Utilities are being required to expand their renewable energy portfolios, and to meet these demands, the market for solar, wind, and geothermal energy is expected to grow more than 10\% per year for the next two decades. With SAM's help, the energy community can continue to analyze the potential of this technology and make educated decisions in applying it.

While SAM's reputation was built on solar power, it has proven to be valuable in other renewable energy arenas. NREL will continue to look for opportunities to expand SAM's powerful analytical tools to incorporate more renewable technologies. For example, the next version of SAM will allow for basic performance modeling of biopower plants. For more information on SAM, or to download the model, access the NREL Energy Analysis website at https://www.nrel.gov/analysis/sam/.

\section{Some Typical Uses of SAM}

- Installers use SAM to determine the effects of orientation and tilt on rooftop solar arrays in their city.

- Developers use SAM's hour-by-hour weather files to determine if a concentrating solar power project makes financial sense for a specific location and electricity rate structure.

- Developers use SAM analyses to show bankers that their project is comparable to projects that have proven to be sound investments.

- Manufacturers show SAM-generated graphs to potential lenders to demonstrate their understanding of the main cost drivers of their renewable energy technology.

- Research and development companies use SAM to analyze the performance benefits versus the financial costs of improving various system components.

- Project managers at the U.S. Department of Energy use SAM to evaluate the effect of their wind energy research investments on the cost of the technologies. They also use it to analyze applications for loan guarantees and to carry out feasibility studies.

- Utilities, graduate students, and federal energy managers use SAM for feasibility studies.

- Software developers use SAM's application programming interface to integrate parts of SAM with their own models.

- Engineering due-diligence firms and utilities use SAM to check assumptions having to do with solar field conditions, as well as the projected hourly and annual energy generation of a proposed project.

- Construction contractors and plant owners use SAM as a tool for "acceptance testing" of concentrating solar power plants.

\section{National Renewable Energy Laboratory}

1617 Cole Boulevard Golden, Colorado 80401-3305 303-275-3000 • www.nrel.gov

NREL is a national laboratory of the U.S. Department of Energy, Office of Energy Efficiency and Renewable Energy, operated by the Alliance for Sustainable Energy, LLC.

NREL/FS-6A42-49150 • October 2011

Printed with a renewable-source ink on paper containing at least $50 \%$ wastepaper, including $10 \%$ post consumer waste.

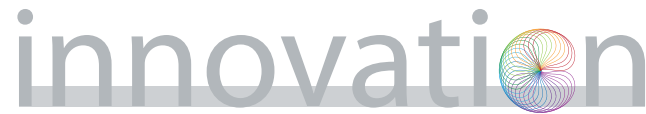

